Peter M. Spieth

Lilla Knels

Michael Kasper

André Domingues Quelhas

Bärbel Wiedemann

Amelie Lupp

Matthias Hübler

Antonio Giannella Neto

Thea Koch

Marcelo Gama de Abreu

\section{Effects of vaporized perfluorohexane and partial liquid ventilation on regional distribution of alveolar damage in experimental lung injury}

Published online: 16 November 2006

(C) Springer-Verlag 2006

\section{Electronic supplementary material}

Supplementary material is available in the online version of this article at http://dx.doi.org/10.1007/s00134-006-0479-9 and is accessible for authorized users.

The online version of the original article can be found at: http://dx.doi.org/10.1007/s00134-006-0428-7

P. M. Spieth $(\varangle) \cdot$ L. Knels $\cdot$ M. Hübler $\cdot$ T. Koch ·

M. Gama de Abreu

Technical University of Dresden and University Hospital, Clinic for Anesthesiology and Intensive Care Therapy, Carl Gustav Carus

Medical College,

Fetscherstrasse 74, 01307 Dresden, Germany

e-mail: p.spieth@web.de

Tel.: +49-351-4582785

Fax: +49-351-4584336

L. Knels · M. Kasper

Technical University of Dresden, Institute of Anatomy, Carl Gustav Carus Medical College,

Dresden, Germany

A. Domingues Quelhas · A. Giannella Neto

Federal University of Rio de Janeiro, Biomedical Engineering

Program, Coordenação dos Programas de Posgraduação de

Engenharia,

Rio de Janeiro, Brazil

B. Wiedemann

Technical University of Dresden, Institute of Biometry and Medical Informatics, Carl Gustav Carus Medical College,

Dresden, Germany

A. Lupp

Friedrich Schiller University, Institute of Pharmacology and

Toxicology,

Jena, Germany

\section{Intensive Care Med (2006) DOI 10.1007/s00134-006-0428-7}

The name of one of the authors was misspelled. The correct author name is given below.

Antonio Giannella Neto 